\title{
Accumulation of Streptococci on Teeth in a Laboratory Microcosm (Artificial Mouth)
}

\author{
HELEN D. DONOGHUE* and C. J. PERRONS \\ University College London Dental School, London WC1E 6JD.
}

Received 26 August 1987; revised 5 November 1987

\begin{abstract}
The accumulation on teeth of three strains of oral bacteria, 'Streptococcus mitior' LPA-1, Streptococcus mutans C67-1, and Streptococcus rattus BHT, was studied from 8 to 90 hours after inoculation. Direct and viable counts demonstrated that strains BHT and C67-1 accumulated more rapidly than strain LPA-1, with fastest growth during the first 16 hours $\left(t_{d 8-16 h} 3 \cdot 6-4 \cdot 8 \mathrm{~h}\right)$. In older cultures, $S$. mutans and $S$. rattus continued to accumulate and a high proportion of the cells were viable. In contrast, ' $S$. mitior' cultures contained many non-viable organisms, possibly due to hydrogen peroxideinduced death. When $S$. rattus was co-cultured with ' $S$. mitior' it was strongly inhibited during the first 24 hours, but increased in proportion after 66 and 90 hours. It was concluded that in the interaction between ' $S$. mitior' and $S$. rattus during initial plaque development, a potentially rapid initial growth rate was of less importance than the ability to antagonise the other organism.
\end{abstract}

KEY WORDS - Streptococcus mutans; Streptococcus rattus; 'Streptococcus mitior'; Oral streptococci; Growth on teeth; Model mouth; Microbial interactions.

\section{INTRODUCTION}

Dental plaque is a surface-associated microbial film in an open ecosystem. It is subjected to a fluctuating nutrient supply from the saliva, crevicular fluid, and the host diet. Under these conditions the behaviour of organisms is likely to differ from that of bacteria in batch or continuous cultures, ${ }^{18}$ and an artificial mouth apparatus has been developed as an appropriate model of the microbial environment on teeth. ${ }^{11}$

'Streptococcus mitior' is probably the most commonly isolated streptococcal species from dental plaque. ${ }^{12}$ It has been shown in previous studies that ' $S$. mitior' can inhibit the mutans streptococcus $S$. rattus BHT by production of hydrogen peroxide when co-cultured for 90 hours in the model mouth. ${ }^{8}$ In addition, pure cultures of ' $S$. mitior' are highly acidogenic in this model, and apparently produce larger quantities of acid than equivalent cultures of S. rattus BHT.?

Mutans streptococci, i.e. Streptococcus mutans and those streptococci with a similar phenotype, are of particular interest because of their acidogenicity

*Author to whom correspondence should be addressed. and association with dental caries, yet it is not understood how these organisms can become established in a potentially inhibitory plaque. Events during the initial period of colonisation of a tooth surface may be crucial in determining whether any one particular organism is more successful than another. In particular, growth rate may be an important ecological factor in microbial accumulation. $^{1}$

Pure culture studies enable growth rate to be determined in the absence of microbial interactions. The aim of the present study, therefore, was to determine the growth rate and viability of ' $S$. mitior' LPA- 1 and $S$. rattus BHT, when grown in pure and mixed culture on teeth, in order to assess the possible role of these factors in the ecology of developing plaque. $S$. mutans $\mathrm{C} 67-1$ was included for purposes of comparison, as it is a more typical example of the mutans streptococci found in human dental plaque. ${ }^{4}$

\section{MATERIALS AND METHODS \\ Microorganisms}

'S. mitior' LPA-1, Carlsson's strain $44,{ }^{5}$ produces extracellular polysaccharide. The taxonomy of this group is still the subject of debate, but due to its 
familiarity in the dental literature, the name ' $S$. mitior' is used in this study. Both strain LPA-1 and $S$. rattus $\mathrm{BHT}^{19}$ have been described previously. ${ }^{8}$ Strain BHT was formerly known as a serotype $b$ strain of $S$. mutans. $S$. mutans C67-1 is a strain which closely resembles the type strain, NCTC $10449 .{ }^{6}$ All three strains were originally human oral isolates but have been maintained for several years in the laboratory.

\section{Cultural Conditions}

The model mouth described by Hudson et al. ${ }^{11}$ was used, but without $\mathrm{pH}$ electrodes. Methods were similar to those described previously. ${ }^{8,11}$ Bacteria were grown on sound, human upper premolar crowns, sliced into halves and mounted back to back to provide a stagnation site. Six replicate culture flasks were generally used per experiment. The assembled apparatus, consisting of reservoirs, tubing, flasks and teeth, was steam-sterilised $\left(134^{\circ} \mathrm{C}\right.$ for $6 \mathrm{~min}$ ). Fluids were filtered into the reservoirs using Duropore membranes (Millipore [UK] Ltd, Harrow, Middlesex).

A synthetic saliva based on bovine submaxillary glycoprotein ${ }^{14}$ was supplied continuously at $0.5 \mathrm{ml} /$ hour. This was delivered to the teeth as separate drops which were retained there until displaced by the next drop. Preliminary work showed that drops fell on the teeth at intervals of 5.08 min (SE 0.31) when saliva only was being supplied. An additional nutrient supplement, SBM broth, was supplied intermittently, for one hour every six hours, at $0.5 \mathrm{ml} /$ hour, and was first available to the organisms eight hours after inoculation. SBM broth contained (g/l): Bacto-casitone (Difco) 20.0; yeast extract (Oxoid) $5 \cdot 0 ; \mathrm{NaCl} 2 \cdot 0 ; \mathrm{K}_{2} \mathrm{HPO}_{4} 4 \cdot 0 ; \mathrm{KH}_{2} \mathrm{PO}_{4} 1 \cdot 0$; $\mathrm{pH} 7 \cdot 0$. After sterilisation $\left(15 \mathrm{~min}\right.$ at $\left.121^{\circ} \mathrm{C}\right)$ glucose was added from a separately sterilised $(10 \mathrm{~min}$ at $\left.110^{\circ} \mathrm{C}\right) 50$ per cent $(\mathrm{w} / \mathrm{v})$ stock solution to give a final concentration of 1 per cent $(w / v)$. Culture flasks were maintained at $35^{\circ} \mathrm{C}$ via their waterjackets, and the apparatus was swept with 5 per cent (v/v) $\mathrm{CO}_{2}$ in air or nitrogen, at $7-14 \mathrm{kPa}(1-2 \mathrm{psi})$. Conditions were not strictly anaerobic with the $\mathrm{N}_{2} / \mathrm{CO}_{2}$ gas mixture, ${ }^{8}$ as fluids in reservoirs were not deoxygenated and the tubing is permeable to gases.

\section{Inoculation}

Bacterial strains were maintained by weekly subculture on brain heart infusion (Oxoid) agar plates.
For inocula, organisms were grown in brain heart infusion broth for 24 hours at $35^{\circ} \mathrm{C}$. From these, rapidly-growing (4 hour) broth cultures were prepared and diluted with fresh, warm broth to give similar numbers of organisms. Inocula were always counted and contained $10^{8}-10^{9} \mathrm{CFU} / \mathrm{ml}$. Before inoculation, the gas and pump were switched on and the synthetic saliva allowed to drop over the teeth for approximately $30 \mathrm{~min}$. A single inoculum $(1.5 \mathrm{ml})$ of a pure culture or freshly-prepared mixture of equal volumes of two strains, was delivered rapidly ( 30 secs) to each tooth via the vaccine cap, using a hypodermic syringe.

\section{Sampling and Counting Procedure}

Teeth were removed at $8,16,24,48,66$ or 90 hours after inoculation. Organisms were released into bottles of $10 \mathrm{ml} 1 / 4$ strength Ringer's solution (Oxoid) by placing containers in an ultrasonic cleaning bath for 2 min. Direct cell and CFU counts were performed on the bacterial suspensions using a counting chamber. The Miles and Misra method was used for viable counts, which were performed in triplicate on SBM agar containing 0.5 per cent $(\mathrm{w} / \mathrm{v})$ glucose. Differential $S$. rattus counts were obtained using agar with $250 \mu \mathrm{g} / \mathrm{ml}$ streptomycin. Plates were incubated for 48 hours in an atmosphere of 10 per cent $(\mathrm{v} / \mathrm{v})$ carbon dioxide and 90 per cent $(\mathrm{v} / \mathrm{v})$ hydrogen.

\section{Analysis of Data}

Before any calculations were performed, bacterial counts were converted to $\log _{10}$ values to ensure normal distribution of the data. The mean and SEM were determined and Student's $t$ was used as a measure of statistical significance $(P<0.05$ was deemed to be significant). Bacterial doubling time $\left(\mathrm{t}_{\mathrm{d}}\right)$ was determined using the formula:

$$
t_{d}=\left(t_{2}-t_{1}\right) \log _{10} 2 / \log _{10} N_{2}-\log _{10} N_{1}
$$

The standard error of the mean difference $\left(\mathrm{S}_{\overline{\mathrm{D}}}\right)$ was calculated, ${ }^{15}$ also the median $t_{d}$ from all possible combinations of pairs of teeth at $t_{1}$ and $t_{2}$.

\section{RESULTS}

\section{Total Counts}

Direct counts demonstrated that there was little clumping of organisms and the mean size of colonyforming units was always less than two bacteria. In 


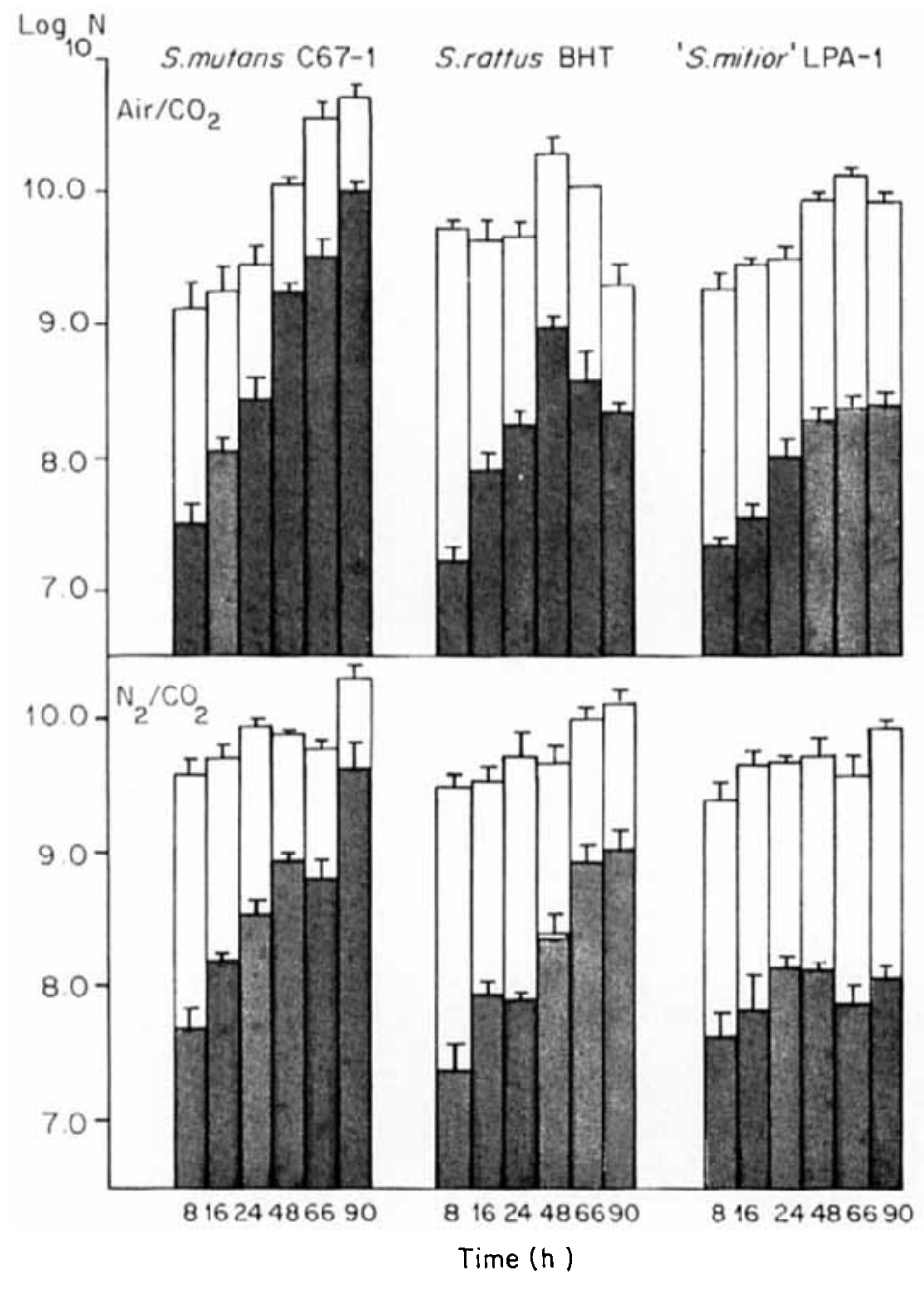

Figure 1. $\log _{10}$ direct and viable count $(+\mathrm{SEM})$ of Streptococcus mutans C67-1, Streptococcus rattus BHT and 'Streptococcus mitior' LPA-1 grown in pure culture on teeth in a model mouth

$\square$ direct count

viable count

all cultures there was evidence of an increase in the total number of organisms on teeth during the experimental period (Fig. 1). This was particularly pronounced with $S$. mutans $\mathrm{C} 67-1$, and the $S$. rattus BHT cultures with the $\mathrm{N}_{2} / \mathrm{CO}_{2}$ gas mixture, where accumulation continued up to 90 hours after inoculation. The total numbers of ' $S$. mitor' LPA-1 on teeth showed a less pronounced increase with time and had stabilised by $24-48$ hours after inoculation. $S$. rattus aerobic cultures showed a drop in direct count between $48-90$ hours $(P<0.001)$.

\section{Viable Counts of Pure Bacteria}

Similar numbers of viable organisms were recovered from all pure cultures 8 hours after inoculation (Fig. 1). However, populations subsequently increased at differing rates. S. mutans and $S$. rattus increased most rapidly between 8 and 16 hours after inoculation (Table 1). $S$. rattus had a faster $t_{d}$ with the air $/ \mathrm{CO}_{2}$ gas mixture $(P<0.02)$, and accumulated more rapidly between 8-16 hours than $S$. mutans $(P<0.02)$. ' $S$. mitior' increased at a slower 
Table 1. Minimum initial bacterial doubling time (hours) of Streptococcus mutans C67-1, Streptococcus rattus BHT and 'Streptococcus mitior' LPA-1, growing in pure or mixed culture on teeth in the model mouth

\begin{tabular}{|c|c|c|c|c|c|}
\hline \multirow[b]{2}{*}{$\begin{array}{l}\text { Gas } \\
\text { Mixture }\end{array}$} & & \multicolumn{4}{|c|}{ Bacterial Strain } \\
\hline & & $\begin{array}{l}\text { S. mutans } \\
\text { C67-1 } \\
(8-16)\end{array}$ & $\begin{array}{l}\text { S. rattus } \\
\text { BHT } \\
(8-16)\end{array}$ & $\begin{array}{l}\text { 'S. mitior' } \\
\text { LPA-1 } \\
(16-24)\end{array}$ & $\begin{array}{l}\text { 'S. mitior' } \\
+ \text { S. rattus } \\
(8-16)\end{array}$ \\
\hline \multirow[t]{2}{*}{$\mathrm{Air} / \mathrm{CO}_{2}$} & $\begin{array}{l}\text { Mean } \\
\left(\mathrm{S}_{\overline{\mathrm{D}}}\right)\end{array}$ & $\begin{array}{c}4 \cdot 38 \\
(1 \cdot 50)\end{array}$ & $\begin{array}{c}3 \cdot 56 \\
(1 \cdot 48)\end{array}$ & $\begin{array}{c}5 \cdot 33 \\
(1 \cdot 47)\end{array}$ & $\begin{array}{c}5 \cdot 67 \\
(1 \cdot 21)\end{array}$ \\
\hline & $\begin{array}{l}\text { Median } \\
\text { (SE median) } \\
n\end{array}$ & $\begin{array}{c}4 \cdot 64 \\
(1 \cdot 29) \\
4\end{array}$ & $\begin{array}{c}3 \cdot 55 \\
(1 \cdot 20) \\
4\end{array}$ & $\begin{array}{c}5 \cdot 43 \\
(1 \cdot 22) \\
3\end{array}$ & $\begin{array}{l}6 \cdot 40 \\
(1 \cdot 11) \\
4\end{array}$ \\
\hline \multirow[t]{2}{*}{$\mathrm{N}_{2} / \mathrm{CO}_{2}$} & $\begin{array}{l}\text { Mean } \\
\left(S_{\bar{D}}\right)\end{array}$ & $\begin{array}{c}4 \cdot 76 \\
(1 \cdot 42)\end{array}$ & $\begin{array}{c}4 \cdot 25 \\
(1 \cdot 66)\end{array}$ & $\begin{array}{c}7.68 \\
(1.72)\end{array}$ & $\begin{array}{l}11 \cdot 81 \\
(1 \cdot 36)\end{array}$ \\
\hline & $\begin{array}{l}\text { Median } \\
\text { (SE median) } \\
\mathrm{n}\end{array}$ & $\begin{array}{c}4 \cdot 63 \\
(1 \cdot 26) \\
4\end{array}$ & $\begin{array}{c}5 \cdot 69 \\
(1.28) \\
4\end{array}$ & $\begin{array}{c}7.91 \\
(1.56) \\
4\end{array}$ & $\begin{array}{c}21 \cdot 14 \\
(1 \cdot 47) \\
4\end{array}$ \\
\hline
\end{tabular}

$\mathrm{n}=$ Number of replicate teeth.

$S_{D}=$ Standard error of the mean difference.

rate than either of the mutans streptococci $(P<0.001)$, and its fastest $t_{d}$ occurred 16-24 hours after inoculation.

The ' $S$. mitior' viable population continued to accumulate slowly under aerobic conditions but remained stable from 24-90 hours when flushed with $\mathrm{N}_{2} / \mathrm{CO}_{2}$. Aerobically-cultured $\mathrm{S}$. rattus attained its maximum population after 48 hours and then declined. However, under partially anaerobic conditions, $S$. rattus continued to accumulate for 66 hours and then stabilised. Viable $S$. mutans increased in numbers throughout the whole 90 hour experimental period, with either gas mixture. After 90 hours $S$. mutans had attained a larger population than 'S. mitior' $(P<0.001)$ or $S$. rattus $(P<0.005)$.

\section{Viability of Pure Cultures}

The ratio of viable to the direct bacterial count was determined (Fig. 2) to give an indication of the viability of organisms recovered from teeth. With all cultures there was a general trend for the proportion of viable organisms to increase with incubation time. The ratio of viable $S$. mutans was generally higher than in any of the other cultures. The proportions of viable $S$. mutans and $S$. rattus increased substantially during the experiment, up to 21 per cent and 11 per cent respectively (Fig. 2). The proportion of viable organisms was low ( $1-3$ per cent) in cultures of 'S. mitior'.

\section{Mixed Cultures}

When ' $S$. mitior' and S. rattus were co-cultured on teeth (Fig. 3), doubling times were slow, especially with the $\mathrm{N}_{2} / \mathrm{CO}_{2}$ gas mixture (Table 1). Under aerobic conditions, numbers of viable $S$. rattus decreased during the initial 24 hours and its proportion of the total viable count (Table 2) fell from 3 per cent at 8 hours to $<0.1$ per cent at 24 hours $(P<0 \cdot 005)$. It subsequently slowly increased in proportion to 0.3 per cent by $66-90$ hours. When the apparatus was flushed with $\mathrm{N}_{2} / \mathrm{CO}_{2}$, proportions of $S$. rattus were $2-40$ times greater $(P<0 \cdot 005)$. A similar pattern was seen, however, of initial decline followed by an increase, in this case, up to 12 per cent by 90 hours. This difference between aerobic and partially anaerobic cultures at 90 hours was statistically highly significant $(P<0 \cdot 001)$.

The viability in mixed cultures was only $1-2$ per cent (Fig. 2). It was clear, however, that from 8 to 24 hours there was a higher proportion of viable organisms in mixed culture under partially anaerobic conditions, when compared with aerobic cultures 


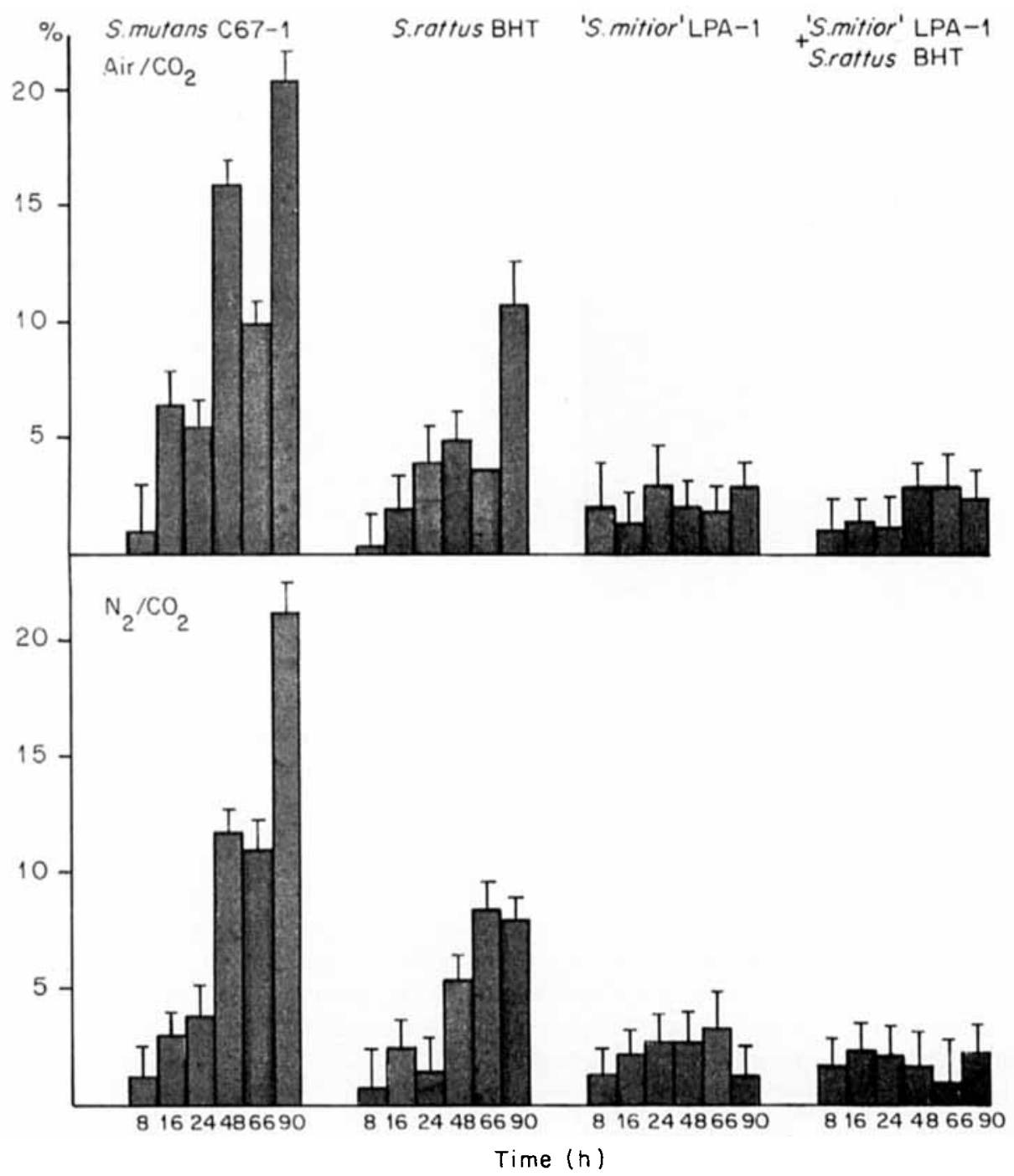

Figure 2. Proportion (\%) (+SEM) of viable count compared with the direct count of streptococci grown in pure or mixed culture on teeth in a model mouth

$(P<0.01-0.05)$. In a pilot experiment with lactoperoxidase included in the saliva, ${ }^{8}$ the proportion of viable organisms in aerobic culture at 24 hours was approximately doubled $(P<0 \cdot 01)$.

\section{DISCUSSION}

As both direct and viable counts increased with time, it was assumed that bacterial growth occurred on the tooth surfaces. The results with pure cultures enable the potential colonisation ability of each organism to be determined in the absence of heterogeneous microbial interactions. It is of interest, therefore, that both strains of mutans streptococci examined had a faster initial growth rate than ' $S$. mitior' LPA-1, and that $S$. mutans C67-1 continued to accumulate throughout the whole experimental period.

Initial doubling times $\left(\mathrm{t}_{\mathrm{d}}\right)$ were comparable with those obtained using animal models. For example, $S$. mutans $\mathrm{T} 2$, in starved gnotobiotic rats, had a $T_{d 12-24 \mathrm{~h}}$ of $4 \cdot 4$ hours, ${ }^{1}$ and $S$. mutans C67-1 inoculated into rats with a conventional flora $^{2}$ had a $t_{d 6-24 h}$ of 4.5 hours. Naturally-occurring strains of $S$. mutans had a $t_{d 6-18 \mathrm{~h}}$ of 3.2 hours when re-colonising the developmental grooves of the 


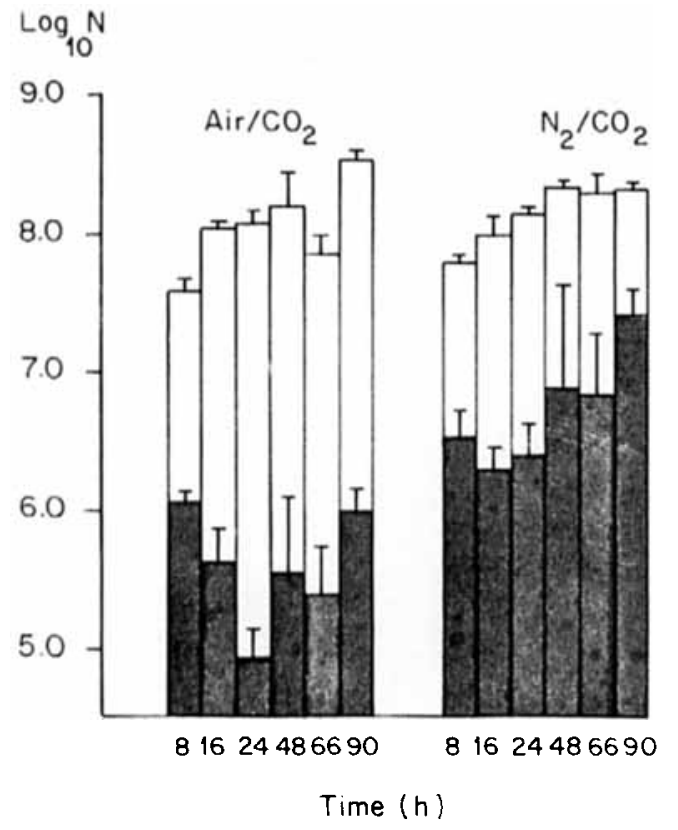

Figure 3. $\log _{10}$ viable count ( $+\mathrm{SEM}$ ) of 'Streptococcus mitior' LPA-1 and Streptococcus rattus BHT grown in mixed culture on teeth in a model mouth

'S. mitior' + S. rattus viable count

differential count of $S$. rattus

first deciduous molars of conventional macaque monkeys. ${ }^{3}$ These results suggest, therefore, that the microbial environment on tooth segments in the model mouth is indeed analogous to that found in vivo, and that the artificial mouth is an appropriate model for the study of dental plaque ecology.

Examination of direct and viable counts enables the proportion to be established. This gives an indication of the viability of the culture, although it is recognised that the use of microscopic counts in this way can give rise to unexpectedly low estimates. ${ }^{13}$ The data have been presented, however, as they enable useful comparisons to be drawn. There is also a possibility of non-viable bacteria being washed off the surface, or of being autolysed. This may have led to the values of microbial viability being over-estimated in the case of the aerobic 90 hour $S$. rattus culture. Otherwise, this does not appear to have been a problem, as the highest proportions of viable organisms were found on teeth with the largest direct counts.

The provision of a glucose-containing nutrient pulse every 6 hours enables all three strains to produce acid, with Stephan-like curves of $\mathrm{pH}$ - fall. ${ }^{7,10,16}$ Comparison of viable counts leads to the conclusion that the more rapid and extensive $\mathrm{pH}$-fall noted previously in young cultures of ' $S$. mitior ${ }^{7,10,11}$ was due to the greater acidogenicity of this strain rather than to any difference in population size. After about 60 hours, however, all three organisms, in pure culture, are exposed to acid for prolonged periods, as the $\mathrm{pH}$ does not return to neutrality before the next glucose pulse. ${ }^{10}$ The high proportions of viable mutans streptococci recovered after 66-90 hours may thus reflect their greater acid tolerance.

Another factor to be considered is hydrogen peroxide $\left(\mathrm{H}_{2} \mathrm{O}_{2}\right)$ production. ' $S$. mitior' LPA-1 produces $\mathrm{H}_{2} \mathrm{O}_{2}$ in the model mouth with either gas mixture ${ }^{8}$ and the low proportion of viable organisms may be due to self-inhibition. The decline in older aerobic $S$. rattus cultures may also be due to self-inhibition by $\mathrm{H}_{2} \mathrm{O}_{2}$, as this strain produces detectable quantities, at least in cell suspensions. ${ }^{17}$ The low proportion of $S$. rattus when co-cultured with ' $S$. mitior' is assumed to be due primarily to the $\mathrm{H}_{2} \mathrm{O}_{2}$ which is produced by strain LPA-1 on teeth. ${ }^{8}$ This is supported by the observation that the proportion of $S$. rattus is lower under aerobic conditions, with a minimum value at 24 hours, just after the ' $S$. mitior' main phase of growth. The increased viability at 24 hours in the presence of lactoperoxidase (LPO) provides indirect evidence for $\mathrm{H}_{2} \mathrm{O}_{2}$ toxicity, as inclusion of LPO in the saliva removes $\mathrm{H}_{2} \mathrm{O}_{2}$ by the production of bacteriostatic hypothiocyanite $\left(\mathrm{OSCN}^{-}\right)$. The high proportion of $S$. rattus in 90 hour mixed cultures under partially anaerobic conditions appears to reflect the greater importance of acid tolerance in conditions with limiting $\mathrm{H}_{2} \mathrm{O}_{2}$ levels.

In conclusion, it is not known whether other strains of the three organisms examined here would exhibit similar differences in accumulation and viability, although it seems likely, as the extent of $\mathrm{H}_{2} \mathrm{O}_{2}$ production and aciduricity are characteristics common to each species. Therefore, considering the initial stages of the establishment of organisms on teeth, the present study suggests that the potential for rapid initial growth by the mutans streptococcus BHT was not sufficient to ensure substantial accumulation when the organisms were co-cultured with a slower-growing $\mathrm{H}_{2} \mathrm{O}_{2}$-producing strain of ' $S$. mitior'. However, after prolonged incubation, with regular glucose supplements, it appears that the combined effects of ' $S$. mitior' self-inhibition, plus the greater aciduricity of the mutans streptococcus, led to an increase in the proportion of $S$. rattus on 
Table 2. Proportion (per cent) (SEM) of Streptococcus rattus BHT differential viable count in the model mouth, when co-cultured with 'Streptococcus mitior' LPA-1

\begin{tabular}{|c|c|c|c|c|c|c|c|}
\hline \multirow{2}{*}{$\begin{array}{l}\text { Gas } \\
\text { Mixture }\end{array}$} & & \multicolumn{6}{|c|}{ Time since inoculation (h) } \\
\hline & & 8 & 16 & 24 & 48 & 66 & 90 \\
\hline $\mathrm{Air} / \mathrm{CO}_{2}$ & $\mathrm{n}$ & $\begin{array}{c}2 \cdot 9 \\
(1 \cdot 3) \\
4\end{array}$ & $\begin{array}{c}0 \cdot 4 \\
(1 \cdot 7) \\
4\end{array}$ & $\begin{array}{c}0 \cdot 1 \\
(1 \cdot 6) \\
4\end{array}$ & $\begin{array}{c}0 \cdot 2 \\
(2 \cdot 0) \\
3\end{array}$ & $\begin{array}{c}0 \cdot 3 \\
(2 \cdot 8) \\
6\end{array}$ & $\begin{array}{l}0 \cdot 3 \\
(1 \cdot 4) \\
11\end{array}$ \\
\hline $\mathrm{N}_{2} / \mathrm{CO}_{2}$ & $\mathrm{n}$ & $\begin{array}{c}5 \cdot 2 \\
(1 \cdot 4) \\
4\end{array}$ & $\begin{array}{c}1 \cdot 9 \\
(1 \cdot 1) \\
4\end{array}$ & $\begin{array}{c}1.7 \\
(1.9) \\
4\end{array}$ & $\begin{array}{c}3 \cdot 3 \\
(4 \cdot 9) \\
2\end{array}$ & $\begin{array}{c}3 \cdot 7 \\
(2 \cdot 1) \\
11\end{array}$ & $\begin{array}{l}11.5 \\
(1 \cdot 4) \\
11\end{array}$ \\
\hline
\end{tabular}

$\mathrm{n}=$ number of replicate teeth.

teeth. This is currently being examined in the model mouth, using $S$. mutans C67-1 and a mixture of typical plaque bacteria. ${ }^{9}$

\section{ACKNOWLEDGEMENT}

We wish to thank Dr R. P. Shellis (MRC Dental Project, University of Bristol) and $\mathrm{Mr}$ A. MacK. Johnston (Royal Veterinary College, London) for the supply of bovine salivary glands, and Dr D. E. Hudson (UCL Dental School) for constructive criticism of the manuscript.

\section{REFERENCES}

1. Beckers HJA, van der Hoeven JS. (1982). Growth rates of Actinomyces viscosus and Streptococcus mutans during early colonization of tooth surfaces in gnotobiotic rats. Infection and Immunity 35, 583-587.

2. Beckers HJA, van der Hoeven JS. (1982). Effect of microbial interaction on the colonization rate of Actinomyces viscosus or Streptococcus mutans in the dental plaque of rats. Infection and Immunity 38, 8-13.

3. Beighton D, Smith K, Hayday H. (1986). The growth of bacteria and the production of exoglycosidic enzymes in the dental plaque of macaque monkeys. Archives of Oral Biology 31, 829-835.

4. Bratthall D, Köhler B. (1976). Streptococcus mutans serotypes: some aspects of their identification, distribution, antigenic shifts and relationship to caries. Journal of Dental Research 55, C15-C21.

5. Carlsson J. (1968). A numerical taxonomic study of human oral streptococci. Odontologisk Revy 19, $137-160$.
6. de Stoppelaar JD, König KG, Plasschaert AJM, van der Hoeven JS. (1971). Decreased cariogenicity of a mutant of Streptococcus mutans. Archives of Oral Biology 16, 971-975.

7. Donoghue HD, Hudson DE, Perrons CJ. (1987). Effect of the lactoperoxidase system on streptococcal acid production and growth. Journal of Dental Research 66, 616-618.

8. Donoghue HD, Perrons CJ, Hudson DE. (1985). The role of $\mathrm{H}_{2} \mathrm{O}_{2}$ and the lactoperoxidase-SCN ${ }^{-}$ $\mathrm{H}_{2} \mathrm{O}_{2}$ system on the interaction between two bacteria originating from human dental plaque, Streptococcus rattus (mutans) BHT and Streptococcus mitior LPA-1, grown on human teeth in an artificial mouth. Archives of Oral Biology 30, 519-523.

9. Donoghue HD, Perrons CJ, Hudson DE. (1986). Establishment of a bacterial 'basic' plaque flora on teeth in an artificial mouth. Journal of Dental Research 65, abstract 305, 521 .

10. Hudson DE. (1984). Microbial interaction and acidogenicity of Streptococcus rattus (mutans) BHT and Streptococcus mitior LPA-1 on surfaces in vitro. Ph.D. Thesis, University of London.

11. Hudson DE, Donoghue HD, Perrons CJ. (1986). A laboratory microcosm (artificial mouth) for the culture and continuous $\mathrm{pH}$ measurement of oral bacteria on surfaces. Journal of Applied Bacteriology 60, 301-310.

12. Marsh PD, Martin MV. (1984). Oral Microbiology, 2nd edn. Aspects of Microbiology 1. Van Nostrand Reinhold (UK) Co Ltd, Wokingham, Berkshire, England, 14.

13. Meynell GG, Meynell E. (1970). Theory and Practice in Experimental Bacteriology, 2nd edn. Cambridge University Press 19. 
14. Shellis RP. (1978). A synthetic saliva for cultural studies of dental plaque. Archives of Oral Biology 23, 485-489.

15. Snedecor GW, Cochran WG. (1967). Statistical Methods, 6th edn. Iowa State University Press, Ames, Iowa, USA, 100-102.

16. Stephan RM. (1944). Intra-oral hydrogen-ion concentrations associated with dental caries activity. Journal of Dental Research 23, 257-266.

17. Thomas EL, Perka KA. (1983). Oxygen metabolism of Streptococcus mutans: uptake of oxygen and release of superoxide and hydrogen peroxide. Journal of Bacteriology 154, 1236-1244.

18. Wimpenny JWT. (1981). Spatial order in microbial ecosystems. Biological Reviews 56, 295-342.

19. Zinner DD, Jablon JM. (1968). Human streptococcal strains in experimental caries. In: Harris RS. (ed) Art and Science of Dental Research. Academic Press, New York and London, 87-109. 